\title{
Determination of the Energy Storage Rate Distribution in the Area of Strain Localization Using Infrared and Visible Imaging
}

\author{
W. Oliferuk • M. Maj $\cdot$ K. Zembrzycki
}

Received: 11 April 2013 / Accepted: 11 October 2013 /Published online: 15 November 2013

(C) The Author(s) 2013. This article is published with open access at Springerlink.com

\begin{abstract}
The presented work is devoted to a new simple method of determination of the energy storage rate (the ratio of the stored energy increment to the plastic work increment) that allows obtaining distribution of this quantity in the area of strain localization. The method is based on the simultaneous measurements of the temperature and displacement distributions on the specimen surface during a tensile deformation. The experimental procedure involves two complementary techniques: i.e. infrared thermography (IRT) and visible light imaging. It has been experimentally shown that during the evolution of plastic strain localization the energy storage rate in some areas of the deformed specimen drops to zero. It can be treated as the plastic instability criterion.
\end{abstract}

Keywords Infrared thermography $\cdot$ Energy storage rate distribution · Strain localization · Plastic instability criterion . Texture evolution

\section{Introduction}

Plastic deformation of the material is an irreversible process. Thus, a part of the mechanical energy $w_{p}$ expended on plastic deformation is converted into heat $q_{d}$. The remaining part $e_{s}$, called stored energy, is stored within the material as an energy related to defects of crystal lattice, mainly dislocation structures,

$e_{s}=w_{p}-q_{d}$

W. Oliferuk $(\bowtie) \cdot$ M. Maj $\cdot$ K. Zembrzycki

Institute of Fundamental Technological Research Polish Academy of

Sciences, ul. Pawinskiego 5B, 02-106 Warsaw, Poland

e-mail: wolif@ippt.gov.pl

W. Oliferuk

Bialystok University of Technology, ul. Wiejska 45 A,

15-351 Bialystok, Poland
The stored energy $e_{s}$ represents a change in internal energy of the deformed material and it is an essential measure of its cold-worked state. This energy was discovered in calorimetric tests performed by Taylor and Quinney [1]. For many years, based on the work of Taylor and Quinney, the part of plastic work stored in the metallic material was considered to be a constant value of about $10 \%$ of the whole plastic work. Nevertheless, further experimental studies have shown that this estimation was wrong [2-19]. It has been found, that the ratio of the stored energy to the plastic work is not constant and depends on deformation level of the tested material. Therefore, there was a need to introduce a concept of the energy storage rate as a measure of energy conversion at each instant of plastic deformation process $[5,13]$. The energy storage rate $Z$ is defined as the plastic work derivative of the stored energy:

$Z=\frac{d e_{s}}{d w_{p}}$,

or the ratio of the stored energy increment $\Delta e_{s}$ to the plastic work increment $\Delta w_{p}$ :

$Z=\frac{\Delta e_{s}}{\Delta w_{p}}$.

The stored energy increment $\Delta e_{s}$ is equal to the difference between the plastic work increment $\Delta w_{p}$ and the increment of energy dissipated as a heat $\Delta q_{d}$,

$\Delta e_{s}=\Delta w_{p}-\Delta q_{d}$.

Therefore, the energy storage rate can be presented as:

$Z=\frac{\Delta e_{s}}{\Delta w_{p}}=1-\frac{\Delta q_{d}}{\Delta w_{p}}$.

The entire deformation process, from the initial state to the fracture of the specimen, can be divided into two stages: macroscopically homogeneous deformation and 
macroscopically heterogeneous one. In our previous work [20], two following indicators of the onset of plastic strain localization were used: non-uniform temperature distribution and non-uniform strain distribution on the surface of the specimen.

It has been shown $[7,15,21]$ that during heterogeneous deformation of polycrystalline material, the energy storage rate rapidly decreases reaching the 0 value and then becomes negative. But in papers [15, 21], only the average value of the energy storage rate for the gauge part of deformed specimen was estimated. Whereas in paper [7], it has been shown that in the area of plastic strain localization the total stored energy $E_{s}$ reaches maximum and then decreases. The decrease in the stored energy corresponds to the negative value of the energy storage rate. In light of those works, the purpose of the present study is to answer the question: What is the energy storage rate distribution along the gauge length of the strained specimen during development of plastic strain localization? To reach the purpose a new simple method of determination of the energy storage rate distribution has been proposed. The method requires similar measurement techniques like in papers [22-26]. There are simultaneous measurements of temperature and displacement distributions on the specimen surface during a deformation process. A new aspect of presented method is the methodology of determination of the energy dissipated as heat. The obtained results are related to the texture evolution.

\section{Determination of the Energy Storage Rate Distribution During Evolution of Strain Localization}

The formula (1.4) shows that the energy storage rate can be calculated by a determination of plastic work increment $\Delta w_{p}$ and corresponding increment of energy dissipated as heat $\Delta q_{d}$. Having determined $\Delta w_{p}$ and $\Delta q_{d}$ for particular sections of the gauge part of the specimen, the distribution of the energy storage rate can be obtained. In order to determine such distribution, simultaneous measurements of the temperature and strain fields on the surfaces of tested specimen were performed. The experimental procedure involves two complementary techniques: i.e. infrared thermography (IRT) and visible light imaging.

In order to determine the strain distribution, markers in the form of graphite dots were painted on the one surface of the specimen (Fig. 1). The initial distance between centres of the dots was equal to $1.3 \mathrm{~mm}$. This way, the surface was divided into sections as presented in Fig. 2. Simultaneously the temperature distribution on the opposite surface of the specimen was measured by means of IR Thermographic System. The surface was covered by soot, to ensure its high and uniform emissivity (soot emissivity $\sim 0.95$ ).

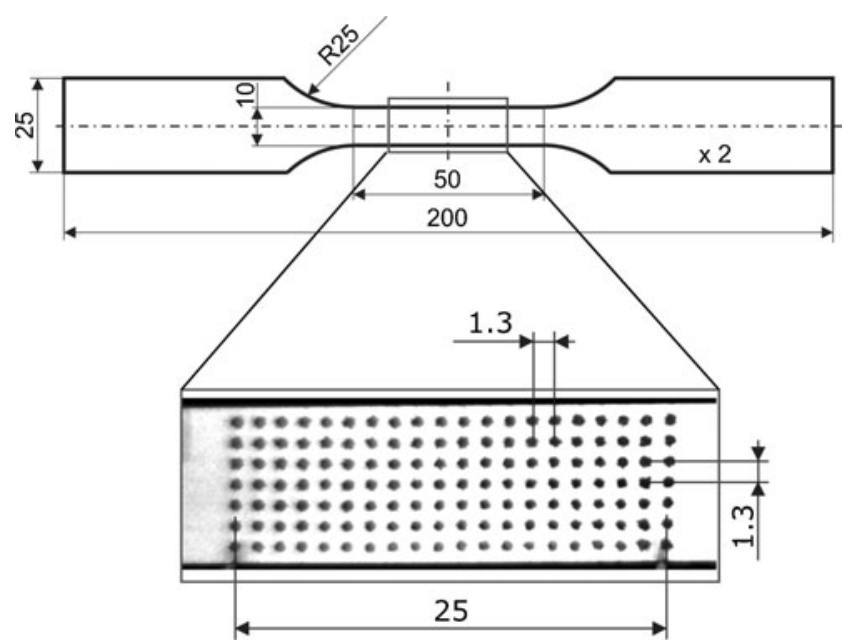

Fig. 1 Specimen geometry and graphite dots (markers) on the gauge part of the specimen

Determination of the Plastic Work Distribution

Specific plastic work during tensile deformation is given by a formula:

$w_{p}=\frac{1}{\rho} \int_{0}^{\varepsilon^{p}} \sigma \cdot d \varepsilon^{p}$

where $\rho$ is a mass density of the tested material, $\sigma$ and $\varepsilon^{p}$ are the true stress and true plastic strain in tensile direction, respectively. Thus, to obtain the distribution of the plastic work in the selected area of the sample, the strain and stress for particular section at each instant of deformation process should be measured.

Let us denote the local true stress and local plastic strain as $\sigma_{y}\left(t, y_{n}\right)$ and $\varepsilon_{y}^{p}\left(t, y_{n}\right)$, respectively. $y_{n}$ is the vertical coordinate of the centre of section $n$.

Strain distribution on the tested surface was derived from displacements of dots recorded by means of a CCD camera

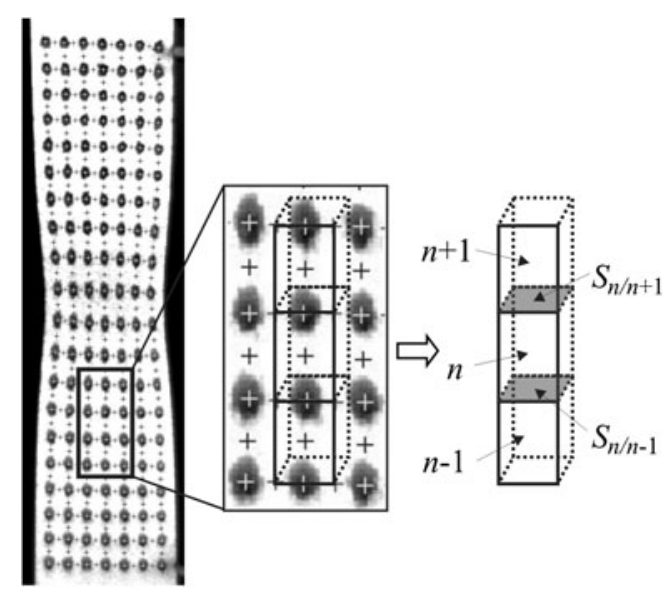

Fig. 2 Division of the gauge part of the specimen into particular sections 
during the deformation process. Taking into account the reference distance between the centres of the dots $l_{0}$ and the current distance as a function of time $l_{y}\left(t, y_{n}\right)$, the true strain $\varepsilon_{y}\left(t, y_{n}\right)$ in the direction of tension for particular section can be calculated as:

$\varepsilon_{y}\left(t, y_{n}\right)=\ln \left(\frac{l_{y}\left(t, y_{n}\right)}{l_{0}}\right)$.

Figure 3 clearly shows that during localization the sections lying on the vertical axis of the specimen have maximal strain in loading direction. Therefore, in the following part of the work, the evolution of the strain $\varepsilon_{y}\left(t, y_{n}\right)$ has been determined for such sections.

During the deformation process, the time dependence of the tensile force $F(t)$ was recorded.

On the basis of the image sequence in a visible range the width of the specimen as the function of time was determined. Then, assuming a constant volume, the current cross-section area $S\left(t, y_{n}\right)$ was obtained. These experimental data allow calculating the average value of stress for the selected crosssection at any time.

$\sigma_{y}\left(t, y_{n}\right)=\frac{F(t)}{S\left(t, y_{n}\right)}$.

However, the stress field over the cross section of the specimen may be non-uniform and the strain localization occurs in the area, where the strain increment requires the lowest plastic work increment. This means that, the increment of the plastic work corresponding to the given increase in strain in the localization area may be slightly lower than calculated (equation (2.1)). Thus, by taking the average value
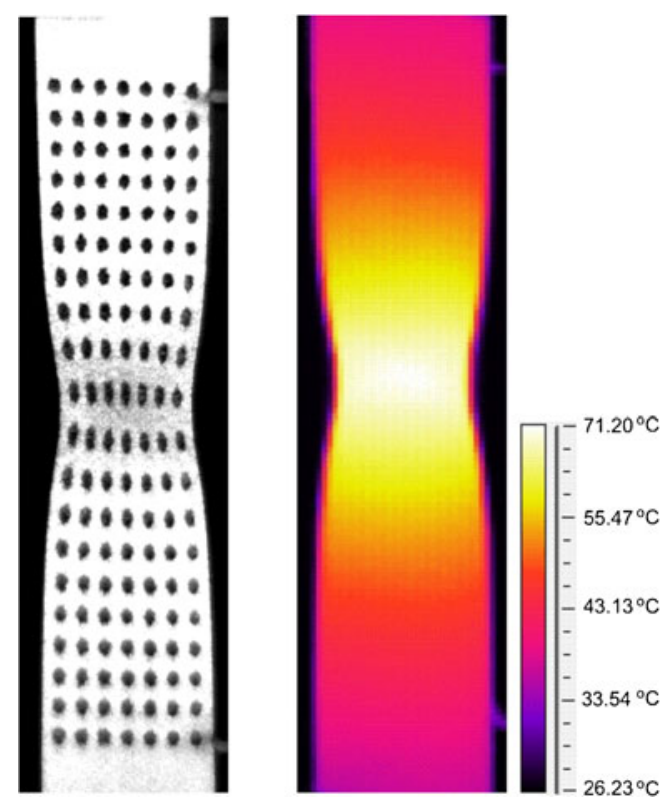

Fig. 3 Example of image of the specimen surface in visible (left) and in infrared range (right) of stress, the energy storage rate may be overestimated (equation (1.4)).

The total strain of each section is equal to the sum of elastic and plastic strains. Thus, assuming that Young's modulus $E$ does not change during the deformation process, the local plastic strain can be calculated from the following formula:

$\varepsilon_{y}^{p}\left(t, y_{n}\right)=\varepsilon_{y}\left(t, y_{n}\right)-\frac{\sigma_{y}\left(t, y_{n}\right)}{E}$.

Based on $\sigma_{y}\left(t, y_{n}\right)$ and $\varepsilon_{y}^{p}\left(t, y_{n}\right)$, the local specific plastic work for particular section $n$ of the specimen was determined as:

$w_{p}\left(t, y_{n}\right)=\frac{1}{\rho\left(t, y_{n}\right)} \int_{0}^{\varepsilon_{y}^{p}\left(t, y_{n}\right)} \sigma_{y}\left(t, y_{n}\right) \cdot d \varepsilon_{y}^{p}$,

where $\rho\left(t, y_{n}\right)=\frac{m_{s}}{V\left(t, y_{n}\right)}$ is the current mass density of a particular section, $m_{s}=$ const $=\rho_{0} \cdot V_{0}=\rho\left(t, y_{n}\right) \cdot V\left(t, y_{n}\right)$ is mass of a section and $V\left(t, y_{n}\right)$ is the current volume of particular section.

\section{Determination of the Distribution of Energy Converted into Heat}

As mentioned above, a part of the energy expended on plastic deformation is dissipated as heat and the remainder is stored in the deformed material and increases its internal energy. The energy dissipated in the form of heat causes an increase in the temperature of the specimen. This increase depends on the strain rate. In the area of the strain localization, the distribution of strain rate is not uniform. This heterogeneity is manifested by a non-uniform temperature field on the specimen surface. Evolution of the temperature field during deformation process was recorded by means of the IR thermography system. On the basis of the obtained experimental data, the average temperature $T\left(t, y_{n}\right)$ as a function of time for each $n$-th section along the axis of the specimen was determined. Such a selection of positions of sections allows avoiding the influence of the specimen edges on the measured temperature values. The initial size of each, considered section is identified by the distance between the centres of the dots and the thickness of the specimen. Thus, the initial volume $V_{0}$ of each section was equal to $(1.3 \times 1.3 \times 2) \mathrm{mm}^{3}$ and the initial cross-section $S_{0}$ was $(1.3 \times$ 2) $\mathrm{mm}^{2}$. Dimensions of the sections were changing during the tensile process. These changes were determined by tracking dot centres in the visible range by means of the CCD camera. All these data have been used to calculate the heat $\Delta q_{d}\left(t, y_{n}\right)$ generated during time interval $\Delta t$ in $n-t h$ section. The interval $\Delta t$ is the reciprocal of the taking frequency.

In order to avoid the influence of the heat convection phenomenon, the displacement rate $2,000 \mathrm{~mm} / \mathrm{min}$ was chosen. At this rate the duration of deformation process was about $1 s$, therefore we are allowed to neglect the heat 
Table 1 Chemical composition of the tested steel

\begin{tabular}{llllllllllllll}
\multicolumn{1}{l}{ Chemical composition (wt. \%) } \\
\hline $\mathrm{C}$ & $\mathrm{Mn}$ & $\mathrm{Si}$ & $\mathrm{P}$ & $\mathrm{S}$ & $\mathrm{Cr}$ & $\mathrm{Ni}$ & $\mathrm{W}$ & $\mathrm{Mo}$ & $\mathrm{Cu}$ & $\mathrm{V}$ & $\mathrm{Ti}$ & $\mathrm{Fe}$ \\
\hline 0.05 & 1.35 & 1.0 & 0.016 & 0.008 & 18.58 & 17.3 & 0.025 & 0.02 & 0.04 & 0.03 & 0.013 & Balance \\
\hline
\end{tabular}

convection. Nevertheless, despite the relatively high displacement rate the deformation process was non-adiabatic mainly due to the heat transport to the grips of the testing machine. It was assumed that heat transfer in the direction perpendicular to the specimen axis with comparison to the heat transport to the grips is negligible.

Thus, taking into account the phenomena considered above and the heat expended for compensation of drop in temperature caused by the thermoelastic effect, the heat $\Delta q_{d}$ $\left(t, y_{n}\right)$ generated during time $\Delta t$ in $n-t h$ section has been calculated according to the following formula:

$$
\begin{array}{r}
\Delta q_{d}\left(t, y_{n}\right)=c_{w} \cdot \Delta T\left(t, y_{n}\right)+\frac{\alpha T\left(t, y_{n}\right) \Delta \sigma_{y}\left(t, y_{n}\right)}{\rho\left(t, y_{n}\right)}+ \\
+\frac{S_{n / n+1}\left(t, y_{n}\right) \cdot \lambda \cdot \Delta t}{\rho_{0} \cdot V_{0}} \cdot\left[\frac{T\left(t, y_{n}\right)-T\left(t, y_{n+1}\right)}{y_{n+1}-y_{n}}\right]+ \\
+\frac{S_{n / n-1}\left(t, y_{n}\right) \cdot \lambda \cdot \Delta t}{\rho_{0} \cdot V_{0}} \cdot\left[\frac{T\left(t, y_{n}\right)-T\left(t, y_{n-1}\right)}{y_{n}-y_{n-1}}\right],
\end{array}
$$

where $\alpha$ is the coefficient of linear thermal expansion, $T(t$, $\left.y_{n}\right)$ is the mean absolute temperature of the considered section, $\Delta \sigma_{y}\left(t, y_{n}\right)$ is the increase in the stress during subsequent time intervals $\Delta t, \lambda$ is the coefficient of thermal conductivity, $c_{w}$ is the specific heat and $V_{0}$ is a volume of considered section. $S_{n / n+1}\left(t, y_{n}\right)$ and $S_{n / n-1}\left(t, y_{n}\right)$ are crosssection areas between neighbouring sections $n / n+1$ and $n / n-$ 1, respectively (see Fig. 2).

The first component of equation (2.6) expresses the heat needed to rise the temperature of a unit mass of the tested material by $\Delta T$. The second describes the heat expended for compensation of the temperature drop due to the thermoelastic effect. The third and fourth components, according to the Fourier's law, take into account the heat transfer between given section $n$ and its neighbours $n / n+1$ and $n / n-1$, respectively. It is worth to notice that the Fourier's law refers to a heat flux. Thus, in order to determine the heat related to a mass unit, the heat flux should be divided by the mass of the section and multiplied by $\Delta t$ and by $S_{n / n+1}\left(t, y_{n}\right)$ or $S_{n / n-1}(t$, $\left.y_{n}\right)$, respectively.

Adding up the heat increments $\Delta q_{d}\left(t, y_{n}\right)$ in the successive time intervals, the time dependence of the energy dissipated as heat $q_{d}\left(t, y_{n}\right)$ for each tested section has been obtained. The energy storage rate for a particular section is defined as $Z=1-\frac{\Delta q_{d}\left(t, y_{n}\right)}{\Delta w_{p}\left(t, y_{n}\right)}$. During non-uniform deformation in the equal time intervals $\Delta t$, the increments of plastic work
$\Delta w_{p}$ are not equal. Thus, $\Delta q_{d}$ was determined for equal increments of $\Delta w_{p}$. In further analysis $\Delta w_{p}=2 \mathrm{~J} / \mathrm{g}$ was taken. Such value was selected in order to reduce the dispersion of increments' ratio $\frac{\Delta q_{d}}{\Delta w_{p}}$. Having obtained $w_{p}(t$, $\left.y_{n}\right)$ and $q_{d}\left(t, y_{n}\right)$ for the considered sections and using the procedure mentioned above the distribution of the energy storage rate was determined.

\section{Experimental Procedure}

The experiments were performed on a specially prepared batch of austenitic stainless steel with chemical composition shown in Table 1. Such composition, similar to a composition of the $304 \mathrm{~L}$ steel, was matched to avoid a phase transformation during the deformation process. The strips with the crosssection $25 \mathrm{~mm} \times 4 \mathrm{~mm}$ were initially annealed at $1,050^{\circ} \mathrm{C}$, water quenched and $50 \%$ cold rolled. From the material prepared this way, the specimens for tensile testing were cut out using an electro-erosion machining (see Fig. 1). Finally, specimens were annealed for $1 \mathrm{~h}$ at $1,100^{\circ} \mathrm{C}$ and water quenched to produce a homogeneous microstructure with a mean grain size about $50 \mu \mathrm{m}$. In order to remove the technological surface layer, the specimens were electro-polished.

Such specimens were strained using MTS 858 testing machine. During the tension the displacement rate was controlled and equal to $2,000 \mathrm{~mm} / \mathrm{min}$. For such displacement rate and given geometry of the specimen (see Fig. 1) the corresponding mean value of strain rate was equal to $6.6 \cdot 10^{-1} s^{-1}$.

In the course of deformation process the infrared and visible range image sequences were recorded simultaneously using the infrared Phoenix and pco.1200hs cameras. An example of such images is shown in Fig. 3. The taking frequency of both cameras was equal to $538 \mathrm{~Hz}$. Such taking frequency was selected in order to take into account the heat transfer between neighbouring sections. Simultaneously, the straining force as a function of time $t$ was measured. The experimental setup is presented in Fig. 4. The analysis of the displacement fields (based on markers tracking) and the assignment of them to the appropriate temperature distributions were performed using MATLAB software. The experiments were performed on three specimens and the average results are presented below. 


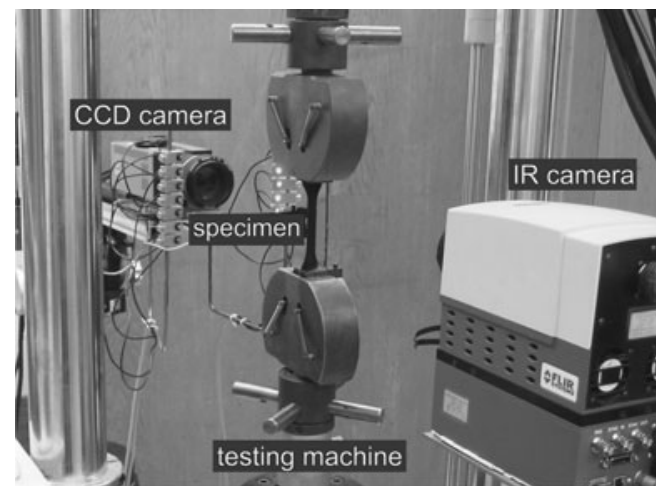

Fig. 4 Experimental setup for simultaneous measurement of displacement and temperature fields

\section{Results and Discussion}

Basing on the experimental data, tensile curves for selected local sections: A, B, C, D, E, lying on the axis of specimen, were calculated (Fig. 5). It can be seen that with an increase in strain, the individual sections of the specimen cease to deform, whereas others are still deforming. Such behaviour is characteristic for the localization of plastic deformation. The obtained stress-strain dependences were used to calculate the plastic work as a function of time for the selected sections lying on the specimen's axis (equation (2.5)).

From the surface temperature field, the distribution of energy dissipated as heat along the specimen axis was determined using a local form of heat equation (equation (2.6)). From energy dissipated as heat vs. plastic work dependences the ratios $\Delta q_{d} / \Delta w_{p}$ were calculated. Then, on the basis of equation (1.4) the energy storage rate $Z$ for each of the considered sections was obtained. The results, as a function of true strain are presented in Fig. 6. Results obtained for different sections are marked by different symbols with different gray intensity, corresponding to stress-strain curves shown in Fig. 5. The obtained results show that the energy storage rate decreases with strain for all considered sections. During the evolution of plastic strain localization some sections cease to deform, which causes a stop in the energy

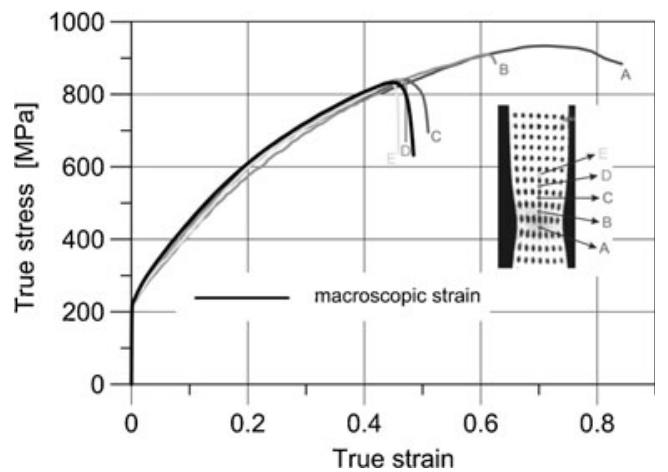

Fig. 5 Stress-strain curves for selected sections of the specimen. Macroscopic strain is marked

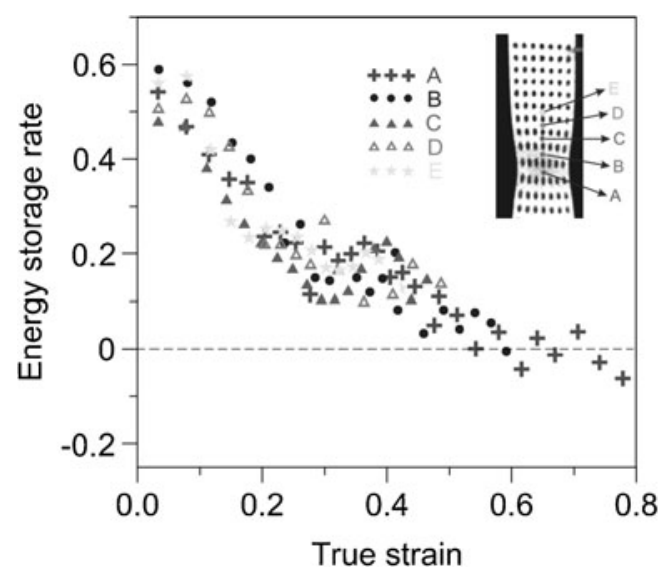

Fig. 6 Energy storage rate as a function of true strain for selected sections of the specimen

storage process in this region, whereas the energy storage rate in the other sections (where deformation still proceeds) drops to zero. It has been shown [21] that for austenitic steel the zero value of the energy storage rate corresponds to the point of Considère stability criterion. Thus, $\frac{\Delta e_{s}}{\Delta w_{p}}=0$ can be treated as the plastic instability criterion based on energy conversion. A confirmation of obtained negative values of $Z$ needs further studies. Negative values of this quantity could be explained by a release of the energy stored in previous deformation stages.

In order to find microscopic interpretation of obtained results the studies of localization phenomena were performed using Transmission Electron Microscopy (TEM) and Electron Back Scattering Diffraction (EBSD) technique. TEM was used for the analysis of dislocation structures at the initial state, whereas the EBSD technique was used for the study of evolution of the crystallographic orientations during the deformation process.

In Fig. 7 the typical microstructure of the initial state of the tested material is presented. One can see that the dislocation density is low and the dislocations are not forming any ordered dislocation structures. It indicates that material is fully recrystallized. The orientation map seen in Fig. 8 shows that grains are randomly oriented and the material does not exhibit any distinct crystallographic or morphological textures.

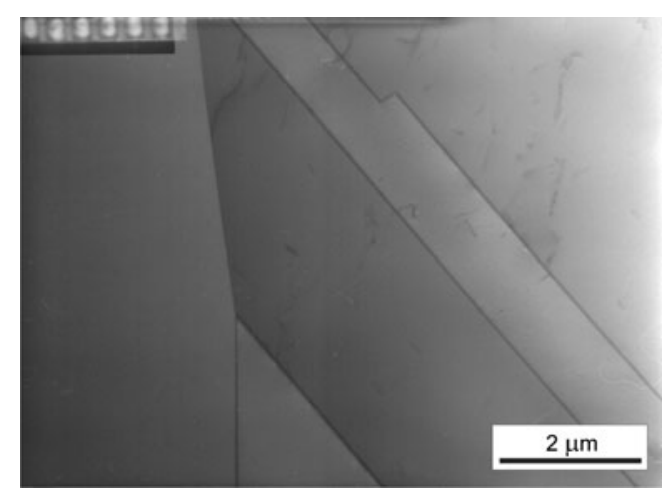

Fig. 7 Typical microstructure of the initial state of tested steel 


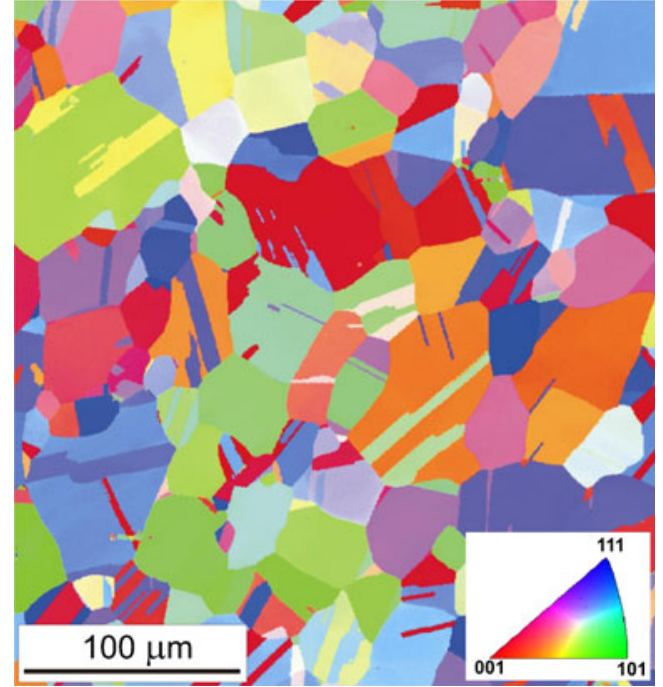

Fig. 8 Distribution of grain orientation in the initial state obtained by EBSD technique

Obtaining such initial state of the material is necessary for both analysis of the energy storage process and its interpretation on the basis of microstructure observations.

In order to obtain the crystallographic orientation maps for different levels of plastic deformation, three specimens were strained to the different values of strain: $0.3,0.4$ and 0.8 . These values correspond to macroscopically uniform deformation, the onset of strain localization and state just before fracture, respectively. Then, the orientation maps were obtained for the selected areas of deformed specimens. The maps are shown in Figs. 9, 10 and 11. One can see that from the onset of plastic strain localization (Fig. 10) the amount of mechanical twins increases. It means that the contribution of twinning in deformation process is growing.

In Figs. 9, 10 and 11 a noticeable trend in the evolution of the orientation of individual grains in direction of two dominant

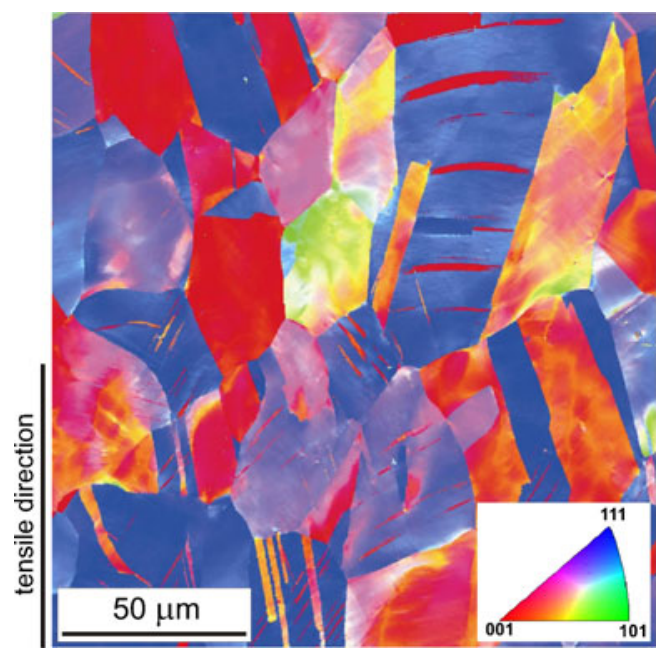

Fig. 9 EBSD image for macroscopically homogeneous deformation

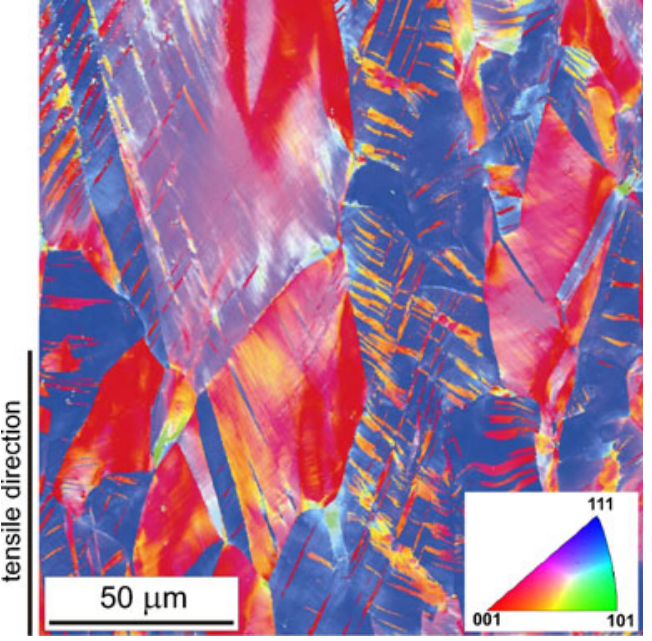

Fig. 10 EBSD image for the onset of plastic strain localization

texture components is observed. It is seen that the development of strain localization is accompanied by further rotation of individual grains in the direction of two texture components. Rotation of grains proceeds in such a way, that the $\{111\}$ type planes become parallel to the planes of maximum shear stress. The angle between the trace of these planes and the tension direction is about $40^{\circ}$. The above analysis shows that in the necking zone, just before the fracture (see Fig. 11), the macroscopic shear of the localized area is possible without change of a crystallographic plane. In other words, the conditions for the crystallographic shear banding are created [27]. This corresponds to the loss of stability of the plastic deformation. On the basis of the presented preliminary results, the authors believe that the zero value of the energy storage rate can be used as a criterion of plastic instability. However, a microstructural interpretation of the energy storage loss just before the fracture requires further studies.

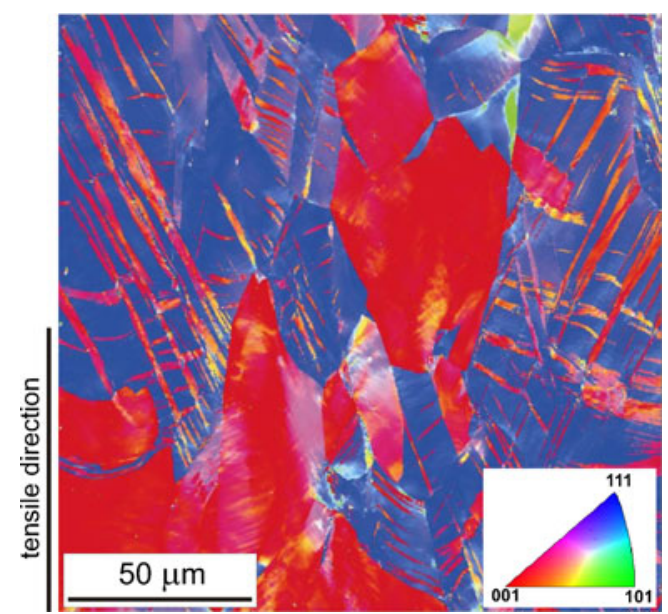

Fig. 11 EBSD image for advanced localization of plastic strain (just before fracture) 


\section{Conclusions}

a) The simple experimental method allowing a determination of the distribution of energy storage rate during a tensile deformation has been presented. Similarly as in the papers [13, 22-26] two following imaging techniques are involved: the IR thermography and visible light imaging. The method does not require a physical simulation of the specimen heating during the plastic deformation, what was necessary in our previous works [10, 11, 15-18, 21]. The new aspect of the method presented in this paper is the methodology of a determination of the energy dissipated as heat.

The presented method can be used to study the behaviour of materials subjected to any modes of loading, for determining the energy conversion during the plastic strain localization.

b) In the area of the plastic strain localization a material achieves a state, in which the energy storage rate $Z$ reaches the 0 value. This means that the material loses an ability to store the energy. Although the energy is supplied to the specimen, its internal energy does not increase. The 0 value of the energy storage rate could be regarded as a plastic instability criterion based on energy conversion. Obtained negative values of $Z$ could be explained by a release of the energy stored in the previous deformation stages but it needs further studies.

c) A preliminary microstructure analysis shows that 0 value of energy storage rate corresponds to the state, in which only two dominant texture components appear. The analysis of the orientation maps shows that in the necking zone, just before the fracture, macroscopic shear of localized area is possible without a change in crystallographic plane. It means, the conditions for the crystallographic shear banding are created [27].

Acknowledgments This work has been supported by the Council of Science (Poland) under Grant No. N N501 009433 (2007-2010).

Open Access This article is distributed under the terms of the Creative Commons Attribution License which permits any use, distribution, and reproduction in any medium, provided the original author(s) and the source are credited.

\section{References}

1. Taylor G, Quinney H (1934) The latent energy remaining in a metal after cold working. Proc R Soc Lond 143:307-326

2. Wolfenden A (1968) The ratio of stored to expended energy during the deformation of copper and aluminium single crystals at $78 \mathrm{~K}$. Acta Metall 16(8):975-980
3. Wolfenden A (1969) The energy stored in gold-silver alloy. Scr Metall 3:429-433

4. Bever MB, Holt DL, Titchener AL (1973) The stored energy of cold work. Prog Mater Sci 17:23-58, Pergamon Press

5. Rönnpagel D, Schwink CH (1978) Measurement of the stored energy of copper single crystals by means of a new deformation calorimetry method. Acta Metall 26:319-331

6. Oliferuk W, Gadaj SP, Grabski MW (1984) Energy storage during the tensile deformation of Armco iron and austenitic steel. Mater Sci Eng 70:131-141

7. Chrysochoos A, Maisonneuve O (1985) Energy balance for elastic plastic deformation at finite strain. C R Acad Sci 300: 985-990

8. Oliferuk W, Świątnicki W, Grabski MW (1993) Rate of energy storage and microstructure evolution during the tensile deformation of austenitic steel. Mater Sci Eng A161:55-63

9. Chrysochoos A, Maisonneuve O, Martin G, Caumon H, Chezeaux JC (1989) Plastic and dissipated work and stored energy. Nucl Eng Des 114:323-333

10. Oliferuk W, Świątnicki W, Grabski MW (1995) Effect of grain size on the rate of energy storage during the tensile deformation of austenitic steel. Mater Sci Eng A197:49-58

11. Oliferuk W, Korbel A, Grabski MW (1997) Slip behaviour and energy storage process during uniaxial tensile deformation of austenitic steel. Mater Sci Eng A224-226:1122-1125

12. Rittel D (1999) On the conversion of plastic work to heat during high strain rate deformation of glassy polymers. Mech Mater 31:131-139

13. Chrysochoos A, Louche H (2000) An infrared image processing to analyse the calorific effects accompanying strain localization. Int $\mathrm{J}$ Eng Sci 38:1759-1788

14. Hodowany J, Ravichandran G, Rosakis AJ, Rosakis P (2000) Partition of plastic work into heat and stored energy in metals. Exp Mech 40:113-123

15. Oliferuk W, Korbel A, Bochniak W (2001) Energy balance and macroscopic strain localization during plastic deformation of polycrystalline metals. Mater Sci Eng A319-321:250-253

16. Oliferuk W, Maj M, Raniecki B (2004) Experimental analysis of energy storage rate components during tensile deformation of polycrystals. Mater Sci Eng A374:77-81

17. Oliferuk W, Maj M (2004) Effect of pre-strain direction on energy storage process during tensile deformation of polycrystal. Mater Sci Eng A387-389:218-221

18. Oliferuk W, Maj M (2009) Stress-strain curve and stored energy during uniaxial deformation of polycrystals. Eur J Mech A/Solids 28: 266-272

19. Chrysochoos A, Wattrise B, Muracciole JM, El Kaim Y (2009) Fields of stored energy associated with localized necking of steel. J Mech Mater Struct 4:245-262

20. Maj M, Oliferuk W (2012) Analysis of plastic strain localization on the basis of strain and temperature fields. Arch Metall Mater 57(4): $1111-1116$

21. Oliferuk W, Maj M (2007) Plastic instability criterion based on energy conversion. Mater Sci Eng A462:363-366

22. Bodelot L, Sabatier L, Charkaluk E, Dufrénoy P (2009) Experimental set-up for fully coupled kinematic and thermal measurements at the microstructure scale of an AISI 316L steel. Mater Sci Eng A501:52-60

23. Pottier T, Toussaint F, Louche H, Vacher P (2013) Inelastic heat fraction estimation from two successive mechanical and thermal analyses and full-field measurements. Eur J Mech A/ Solids 38:1-11

24. Badulescu C, Grédiac M, Haddadi H, Mathias J-D, Balandraud X, Tran H-S (2011) Applying the grid method and infrared thermography to investigate plastic deformation in aluminium multicrystals. Mech Mater 43:36-53 
25. Dumoulin S, Louche H, Hopperstad OS, Børvik T (2010) Heat sources energy storage and dissipation in high-strength steels: experiments and modelling. Eur J Mech A/Solids 29: 461-474

26. Saai A, Louche H, Tabourot L, Chang HJ (2010) Experimental and numerical study of the thermo-mechanical behaviour of Al bi-crystal in tension using full field measurements and micromechanical modelling. Mech Mater 42:275-292

27. Paul H, Driver JH (2007) Deformation structure and texture transformations in twinned fcc metals: critical role of microand macro- scale shear bands. Mater Sci Forum 550:521526 